\title{
Evolución de la delincuencia en España: Análisis longitudinal con encuestas de victimización ${ }^{1}$
}

\author{
Manuscrito recibido el 11 de febrero de 2010 / Publicado el 12 de abril de 2010
}

\author{
Elisa García España ${ }^{2}$ José Luis Díez Ripollés, Fátima Pérez Jiménez, \\ María José Benítez Jiménez \& Ana Isabel Cerezo Domínguez
}

\author{
Observatorio de la Delincuencia (ODA). Instituto andaluz \\ interuniversitario de Criminología. Universidad de Málaga
}

\section{RESUMEN}

En España no contamos con encuestas de victimización periódicas debido a que ningún organismo ha asumido esta relevante tarea. Para conocer el volumen y evolución de la delincuencia en este país ha habido que recurrir, hasta el momento, a las estadísticas oficiales como único referente, siendo por todos conocidas las deficiencias que presentan estas fuentes por sí solas para tales fines.

La investigación que presentamos en este artículo muestra un análisis de la realidad delictiva en España a partir de encuestas de victimización a nivel nacional. La comparación longitudinal se ha realizado entre los dos pases internacionales de la ICVS (1989 y 2005) en los que España participó, y la encuesta realizada por el Observatorio de la Delincuencia (ODA) en 2009 con el mismo cuestionario ICVS. Con estas tres encuestas se ha podido realizar un análisis de la evolución de la delincuencia en España en las últimas dos décadas.

Como comprobará el lector a lo largo de estas páginas, a pesar de que la opinión pública considera que la delincuencia en España ha aumentado en las décadas analizadas, los resultados de las encuestas de victimización muestran que en realidad ha descendido.

Palabras clave: encuestas de victimización, evolución de la delincuencia, percepción social.

\footnotetext{
${ }^{1}$ Esta investigación se ha desarrollado en el marco del proyecto de investigación LA SEGURIDAD CIUDADANA COMO CRITERIO INSPIRADOR DE LA INTERVENCIÓN PENAL (SEJ200607242/JURI), financiado por el Programa Nacional de Investigación Científica, Desarrollo e Innovación Tecnológica de la Secretaría de Estado de Universidades e Investigación del Ministerio de Educación y Ciencia.

${ }^{2}$ Correspondencia: elisa@uma.es
}

Revista Española de Investigación Criminológica

Artículo 2, Número 8 (2010) $\quad$ www.criminología.net

ISSN: $1696-9219$ 


\begin{abstract}
In Spain we do not have periodic victimization surveys since no agency has undertaken this important task. In order to determine crime levels and trends, national researchers have been forced to focus on official statistics, despite the known weaknesses of these sources.

The present research displays an analysis of the current Spanish criminality, as shown by victimization surveys nationwide. The longitudinal comparison was made between the two passes (1989 and 2005) of the International Crime Victim Survey (ICVS) in which Spain participated, and polls conducted by the Observatory for Crime in 2009 with the same ICVS questionnaire. Having these three surveys in sight, we have been able to describe and to assess the evolution of crime in Spain in the last two decades.

As the reader will see through these pages, although public opinion assumes that crime in Spain has increased through the last twenty years, victim surveys for these decades show that crime in Spain has continuously dropped.
\end{abstract}

Key words: Victim Surveys, crime trend, social perception.

\title{
I. ANTECEDENTES
}

En España la disponibilidad de encuestas de victimización nacionales ha sido siempre muy limitada, ya que ningún organismo oficial ha asumido hasta el momento la tarea de realizarlas de modo sistemático. El Centro de investigaciones sociológicas CIS- ha sido el organismo que mayor atención ha prestado a las encuestas de victimización en nuestro país; sin embargo, desde 1978 a la actualidad tan solo ha llevado a cabo cinco encuestas nacionales, sin periodicidad y con una técnica (selección muestral, cuestionario, etc) que hace imposible la incorporación de España a la comparación internacional.

Para conocer el volumen y evolución de la delincuencia en España ha habido que recurrir hasta ahora a las estadísticas policiales y judiciales, a pesar de las conocidas carencias que presentan respecto a los delitos que no llegan a ser conocidos por estas instancias y respecto a la limitada publicidad de sus datos.

Las estadísticas oficiales ofrecen desde hace años una evolución de la delincuencia en España en casi continuo crecimiento, como se observa en los gráficos $n^{\circ}$ 1 y 2.

Revista Española de Investigación Criminológica

Artículo 2, Número 8 (2010) $\quad$ www.criminología.net

ISSN: $1696-9219$ 
Gráfico $n^{0}$ 1. Evolución de los hechos conocidos por la policía

1980-2008

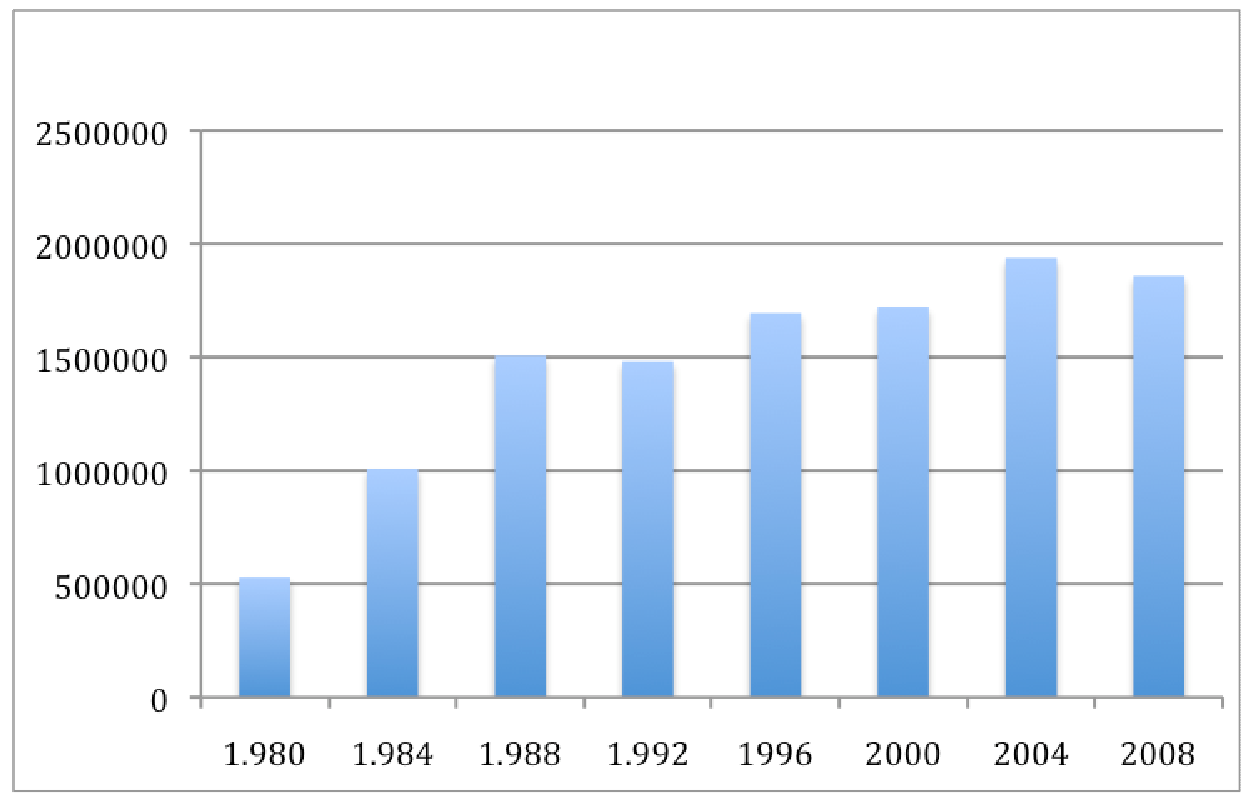

Fuente: Anuarios estadísticos MIR

Gráfico nº 2: Evolución de la densidad delictiva en España.

Índice por 1.000 habitantes

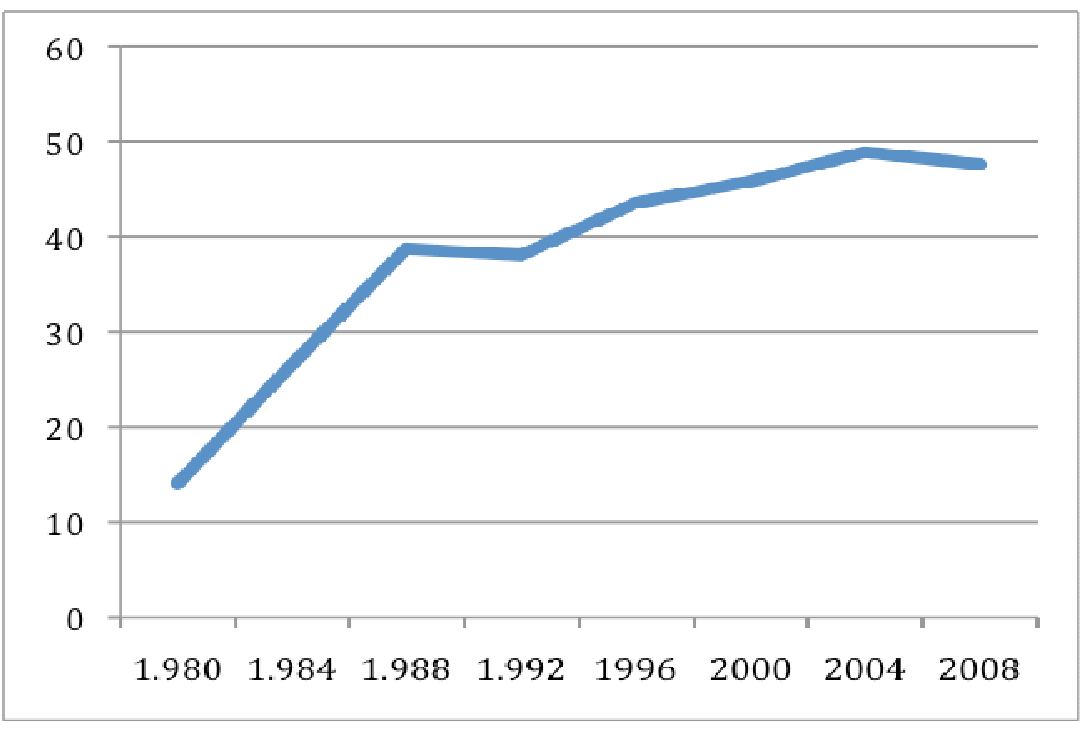

Fuente: Datos del MIR y del INE

Ante este panorama ha habido intentos por tratar de demostrar que el incremento de la delincuencia conocida oficialmente y publicada en las estadísticas policiales podía no ser representativo de la delincuencia sufrida. El objetivo de estos trabajos ha sido aportar información que dotara de mayor racionalidad a las reformas legislativas

Revista Española de Investigación Criminológica

Artículo 2, Número 8 (2010) $\quad$ www.criminología.net

ISSN: $1696-9219$ 
inmersas en derroteros punitivistas y justificadas en parte por los datos extraídos de las estadísticas oficiales. No obstante, esos estudios se han realizado a partir de un análisis más profundo de las propias estadísticas policiales, y no han podido contar con otros datos empíricos complementarios (entre otros, GARCÍA ESPAÑA/PÉREZ JIMÉNEZ, 2004; DÍEZ RIPOLLÉS, 2006; CID MOLINÉ, 2008; GARCÍA PÉREZ, 2008).

Además, investigaciones precedentes, a partir de las encuestas internacionales de victimización, colocan a España entre los países pesimistas en la relación tasas reales de delincuencia y miedo al delito, junto con Portugal, en una clasificación de tres grupos, donde los otros dos son los países optimistas -Suecia y Países Bajos- y los realistas Francia, Suiza e Inglaterra- (REDONDO, S. et al, 2006). Esta perspectiva pesimista española presupone que los ciudadanos creen que la delincuencia ha crecido en los últimos años, cuando en realidad ha bajado, y que, por tanto, el miedo declarado trae consecuencia de dicha percepción. A la inversa ocurre en Suecia y Países Bajos: El bajo nivel de miedo al delito no se corresponde con el crecimiento de las tasas de victimización.

Por tanto, se hacía necesario un trabajo de campo que nos mostrara la evolución y volumen de la delincuencia sufrida por las víctimas y percibida por la ciudadanía a partir de información no suministrada por las estadísticas oficiales. La investigación realizada en el Observatorio de la delincuencia (ODA) perseguía dos precisos objetivos: En primer lugar, dibujar la tendencia de la delincuencia en España en las últimas dos décadas; y, en segundo lugar, conocer la percepción social de la evolución de la delincuencia en ese mismo periodo.

El equipo de la sección de Málaga del Instituto andaluz interuniversitario de Criminología, desde la temprana encuesta realizada sobre la ciudad de Málaga en 1994 con la técnica ICVS (DÍEZ RIPOLLÉS et al, 1996) y cuyos resultados han podido ser cotejados con los de la encuesta llevada a cabo en la misma ciudad en 2005 (GARCÍA ESPAÑA et al, 2006), ha desarrollado en los últimos años encuestas sobre el total de capitales provinciales andaluzas (8) al abrigo del ODA (GARCÍA ESPAÑA et al, 2007 y 2008). Ello le ha permitido obtener una visión muy completa de la delincuencia urbana de una región populosa, Andalucía, que supera los 8 millones de habitantes, algo que no parece que tenga muchos precedentes.

España ha participado hasta ahora en dos pases de la International Crime Victims Survey (ICVS), los realizados en 1989 y en 2005 (EU ICS). El ODA, para mejorar los

Revista Española de Investigación Criminológica

Artículo 2, Número 8 (2010) $\quad$ www.criminología.net

ISSN: $1696-9219$ 
elementos de comparación, y aprovechando la experiencia ya adquirida en encuestas de victimización, se propuso llevar a cabo una encuesta a nivel nacional en 2009 con base igualmente en el internacionalmente validado cuestionario ICVS.

Lo que sigue ahora es justamente un análisis de la evolución de la delincuencia en España, y de su percepción social, a partir de los resultados obtenidos en esa encuesta nacional y en los dos pases europeos precedentes. Si bien en este artículo se analiza la tendencia de la delincuencia sufrida por la víctima y percibida por la ciudadanía en España, el informe completo con el análisis de todos los resultados de la encuesta de 2009 se encuentra publicado en una monografía de ese mismo año codirigida por DÍEZ RIPOLLÉS y GARCÍA ESPAÑA, bajo el título Encuesta a víctimas en España.

\section{METODOLOGÍA}

a. Fortalezas y debilidades de la metodología empleada

Son varias las ventajas que se derivan de las encuestas de victimización como método de investigación social: Se puede estimar el porcentaje de población victimizadas; se conocen las circunstancias en las que ocurrieron las diversas infracciones; se adquiere información sobre las causas por las cuales no se denuncian determinados delitos; se estima la tasa de los delitos no denunciados, lo cual posibilita realizar la estimación total de las infracciones cometidas; se recaba la opinión de la población respecto al funcionamiento de la Administración de Justicia; y se obtiene un barómetro del sentimiento de seguridad ciudadana. De ahí que las encuestas de victimización sean un método importante para el estudio interdisciplinar del fenómeno global de la inseguridad ciudadana y su uso se haya extendido por todo el mundo, habiéndose consolidado especialmente, aunque no sólo, en el mundo anglosajón. Como ejemplo de ello hay que referirse a la encuesta americana Nacional Crime Victimization Survey -NCVS- (http://www.icpsr.umich.edu/NACJD/NCVS), o la British Crime Survey (http://www.statistics.gov.uk/ssd/surveys/british_crime survey.asp), ambas comparables entre sí.

No obstante, en términos científicos este instrumento ha mostrado algunos defectos (entre otros, MIRANDA LÓPEZ, 1993; GIDDENS, 1991; HAGAN, 1989; ALVIRA MARTÍN/ RUBIO RODRÍGUEZ, 1982): Inexactitud de la memoria humana, con el llamado efecto telescopio, consistente en recordar hechos lejanos como recientes, 
o con exageraciones o falsedades; dificultades en la delimitación conceptual de los delitos, con un uso del lenguaje poco claro; incapacidad para detectar los delitos "sin víctimas" o los no definidos como tales por la víctima; etc.

Otras carencias metodológicas tienen que ver con la falta de criterios uniformes en su utilización: En primer lugar, la delimitación del periodo de tiempo objeto de análisis entre distintas encuestas debe ser el mismo para poder comparar resultados; sin embargo, en algunas se pregunta por los delitos sufridos durante toda la vida, en otras por los del año anterior y en otras por los de los últimos cinco años. En segundo lugar, existen diferencias importantes entre la delincuencia urbana y rural, por lo que encuestas realizadas sobre poblaciones distintas tampoco son comparables. En tercer lugar, existen grupos de alto riesgo delictivo: Las personas que se encuentran en su casa y que están motivadas a participar en una entrevista normalmente son las que menos delitos sufren; según la técnica que se utilice (bola de nieve, ruta aleatoria o estratificada a través de la guía telefónica) esta población estará más o menos representada, pudiendo dar un elevado error muestral. En cuarto lugar, varía en exceso de un estudio de victimización a otra tanto el número de rechazos como el número de delitos que se reconoce haber sufrido; ello dependerá de la técnica que se utilice para hallar la tasa de victimización (encuesta, entrevista telefónica o personal, etc). En quinto lugar, existe disparidad en la definición de sujeto pasivo: En unas se pregunta por los delitos sufridos por cualquier miembro de la familia, y en otras sólo por los sufridos por la persona encuestada. En sexto lugar, la confusión en la forma de tipificar los hechos origina resultados muy variados. No hay que olvidar, además, que los delitos frustrados o de menor importancia son más frecuentes que los delitos consumados o graves, por lo que una encuesta que incluya faltas y delitos frustrados siempre va a dar cifras más elevadas que la encuesta que los excluya (STANGELAND, 1996). Y, por último, los cambios técnicos o de procedimiento en una misma encuesta de un pase a otro a lo largo del tiempo impiden análisis de tendencia sin los adecuados correctores (HEIMER et al, 2009; SCHWART et al, 2009).

De ahí que, de cara al conocimiento de la evolución de la delincuencia como material complementario a las estadísticas oficiales que sirvan de referente en el buen hacer de la política criminal española y para tener cotejos que nos permitan valorar el volumen de la delincuencia según encuestas de victimización, es importante metodológicamente tener un modelo de encuesta que permita comparaciones 
longitudinales y transversales (BOUTEN et al, 2003).

Un modelo de encuesta que ha superado los defectos anteriores y que se ha diseñado para cumplir esa función es la Encuesta internacional a víctimas de delitos (ICVS) del Instituto de investigación interregional sobre la justicia criminal de las Naciones Unidas (UNICRI). De hecho, la ICVS es el proyecto más importante de normalización de estudios tendentes a conocer el volumen y la evolución de la delincuencia (BAS/ GARCÍA-VALDECASAS, 2003).

No obstante, es una encuesta que presenta aún algunos problemas con respecto a la representatividad poblacional, como consecuencia de la técnica que utiliza: La encuesta telefónica a hogares a través de la técnica CATI (sistema que permite hacer encuestas telefónicas y en línea y, al mismo tiempo, permite recoger las respuestas en una base de datos de forma directa) impide el acceso a la población que solo utiliza teléfonos móviles o a los hogares que no tienen telefonía fija. Precisamente la población que sólo usa teléfonos móviles tiene tasas de victimización más altas por ser relativamente más joven y ser la que presenta un mayor riesgo de victimización (JOHNSON, 2006). Además, el uso de esta técnica excluye de su ámbito de aplicación a otros sectores de la población, como personas institucionalizadas, población flotante, personas jurídicas, etc. También deja fuera la victimización infantil, no sólo por lo inapropiado de la técnica, sino también por la definición del objeto de estudio, que es la población de 16 años o más. Algunas de estas deficiencias no son exclusivas de la técnica usada en la encuesta ICVS, sino que se comparten con otras ya consolidadas como, por ejemplo, la NCVS.

Sin embargo, hay que reconocer que la ICVS adquiere su máximo alcance al hacer posible comparaciones longitudinales e internacionales, habiendo superado muchos de los defectos puestos de manifiesto por los expertos.

\section{b. Capacidad de análisis comparativo}

El ODA ha utilizado para la encuesta de victimización a nivel nacional el método de la International Crime Victims Survey (ICVS). No sólo compartimos un mismo modelo de encuesta adaptado al caso español, sino también la tecnología CATI en el trabajo de campo y la explotación de datos. En cuanto al tamaño y la selección muestrales, hay cierto matiz diferencial: En el pase ODA 2009 se realizó la encuesta a poblaciones de 
más de 50.000 habitantes, mientras que en los pases europeos precedentes en los que participó España se seleccionó la muestra de toda la población de cada país. Otra diferencia es que en los pases internacionales de 1989 y 2005 no se incluyó en la encuesta para España la pregunta relativa a "daños de coche”, pregunta que sí incluimos en nuestra encuesta de 2009. Por este motivo, en el análisis de datos usamos para la comparación las tasas de victimización halladas para 10 de los 11 delitos preguntados en nuestra encuesta, pues excluimos los datos sobre daños a coches. Además de los "daños a coches" se ha tenido que prescindir también de las "agresiones sexuales" para proceder a la comparación longitudinal de las tasas de delitos totales y denuncia, por lo que en el análisis de esas tasas el número de delitos queda reducido a 9.

c. Ficha técnica

A continuación detallamos de forma resumida los rasgos más sobresalientes de la metodología de nuestro trabajo de campo:

Universo y ámbito de aplicación:

Población de 16 años y más en capitales de provincia y municipios de más de 50.000 habitantes. En conjunto, un total de 23.494.676 personas a 1 de enero de 2007.

Muestra:

1400 encuestas

Margen de error:

El margen de error para el conjunto es del $\pm 2,62 \%$, con un nivel de confianza del $95,5 \%$ y para $\mathrm{p}=\mathrm{q}=0,5$.

Trabajo de Campo:

El trabajo de campo se desarrolló entre el 17 de febrero y el 1 de abril de 2009 por entrevistadores especializados de EDIS, S.A., en las oficinas de EDIS en Madrid.

Método de recogida de la información:

La información se ha recogido mediante encuestas telefónicas a través del sistema CATI.

Tipo de datos y periodo contemplado:

Datos sobre victimización relativos al periodo 2004-2008, actitud hacia el delito y la policía, los juzgados, los juzgados de menores y las prisiones, actitudes punitivas, opinión sobre la severidad judicial, la delincuencia percibida y la influencia de los medios de comunicación.

Revista Española de Investigación Criminológica

Artículo 2, Número 8 (2010) $\quad$ www.criminología.net

ISSN: $1696-9219$ 


\section{TENDENCIA DE LA DELINCUENCIA EN ESPAÑA}

\section{Tasas de victimización}

\section{a. Evolución de la delincuencia}

Las tasas de victimización que han sufrido uno o más delitos, halladas en los tres pases de las encuestas referidas para el último año y los últimos cinco años anteriores a cada uno de los pases, muestran una tendencia descendente, como puede apreciarse en el gráfico $\mathrm{n}^{0} 3$.

\section{Gráfico n 3: Evolución de la tasa de victimización en España}

(10 delitos) (\%)

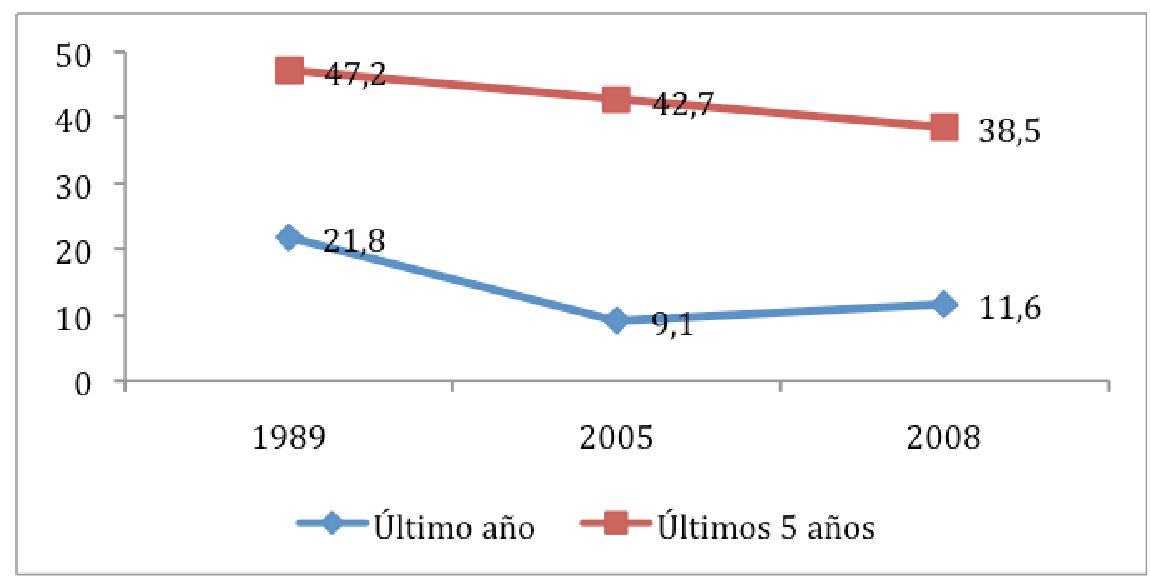

La delincuencia en España está descendiendo desde hace 20 años según los datos mostrados por las encuestas de victimización referidos a la delincuencia común, lo que contrasta con la línea ascendente que muestran las estadísticas policiales españolas (gráfico $\mathrm{n}^{0} 1$ ), con las percepciones sociales -como se comprobará más adelante- $\mathrm{y}$, sobre todo, con los discursos de los agentes políticos, que llevan tiempo sirviéndose del pretendido aumento de la delincuencia para adoptar todo tipo de iniciativas rigoristas populistas en el ámbito penal.

\section{b. Evolución por tipologías delictivas}

a. Robo de coches

En los últimos veinte años se aprecia, al comparar la secuencia de pases de la encuesta internacional de 1989, 2005 y 2008, que la tasa de victimización de este delito durante los últimos cinco años desciende (gráfico $n^{\circ} 4$ ), no ocurriendo así con la tasa de denuncia en ese mismo periodo, que se incrementó en más de ocho puntos,

Revista Española de Investigación Criminológica 
convirtiéndose en el delito más manifestado a la policía (DÍEZ RIPOLLÉS/GARCÍA ESPAÑA, 2009).

\section{Gráfico n 4: Evolución de los delitos de robo de coches (\%)}

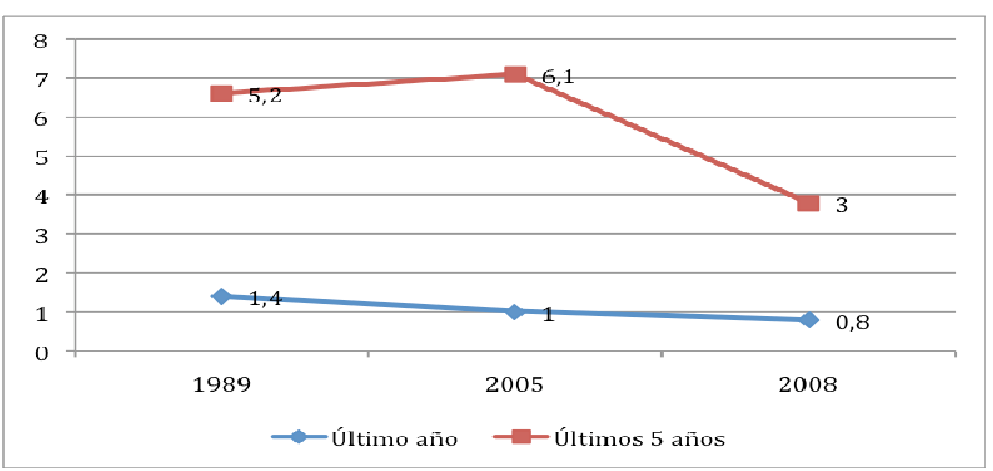

b. Robo de objeto de coches

La tasa de victimización de esta conducta es superior a la observada en el robo de coche, tanto durante los últimos cinco años como en 2008 (15,6\%; 4,4\%), y también es más frecuente ser víctima de este delito en más de una ocasión que de robo de coche. La tendencia observada en la victimización de este delito a través de las encuestas internacionales (gráfico $\mathrm{n}^{\circ}$ 5) en el periodo de tiempo de los últimos cinco años es descendente, mientras que durante el último año puede indicarse que la victimización en 2008 es más baja que en 1989 pero no que en 2005.

\section{Gráfico n $^{0}$ 5: Evolución de los robos de objeto de coches (\%)}

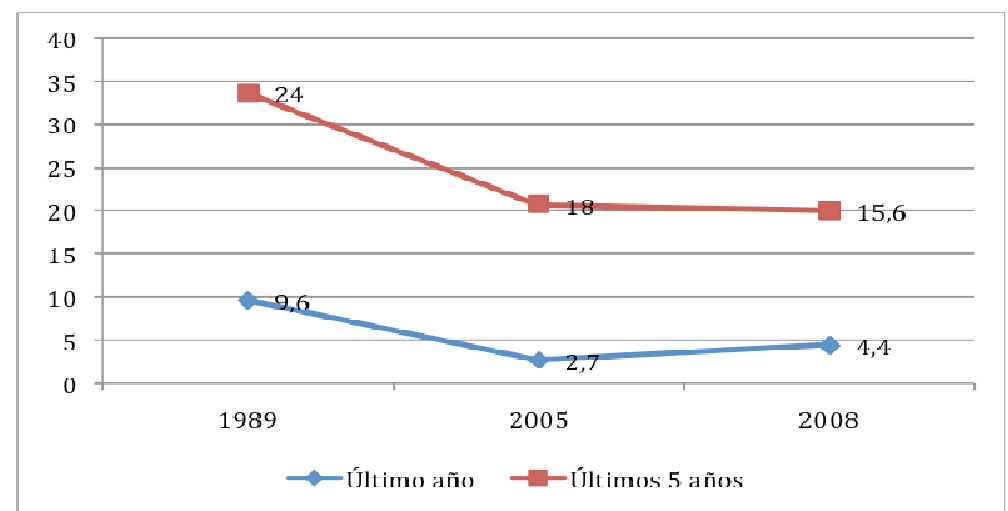

c. Robo de motos o ciclomotores.

Las tasas de victimización del delito de robo de moto durante los últimos cinco años $(1,9 \%)$ y durante el último año $(0,3 \%)$ coincidieron con las obtenidas en nuestro

Revista Española de Investigación Criminológica 
país en la encuesta internacional de victimización de 2005 (gráfico $\mathrm{n}^{\circ}$ 6). La tasa de denuncia de robo de motos es muy elevada durante los últimos cinco años, llegando al $76,9 \%$. Por el contrario, en el último año (2008) se aprecia un índice mucho más bajo, que no supera el 50\% (DÍEZ RIPOLLÉS/GARCÍA ESPAÑA, 2009).

\section{Gráfico n 6: Evolución de los robos de motos o ciclomotor (\%)}

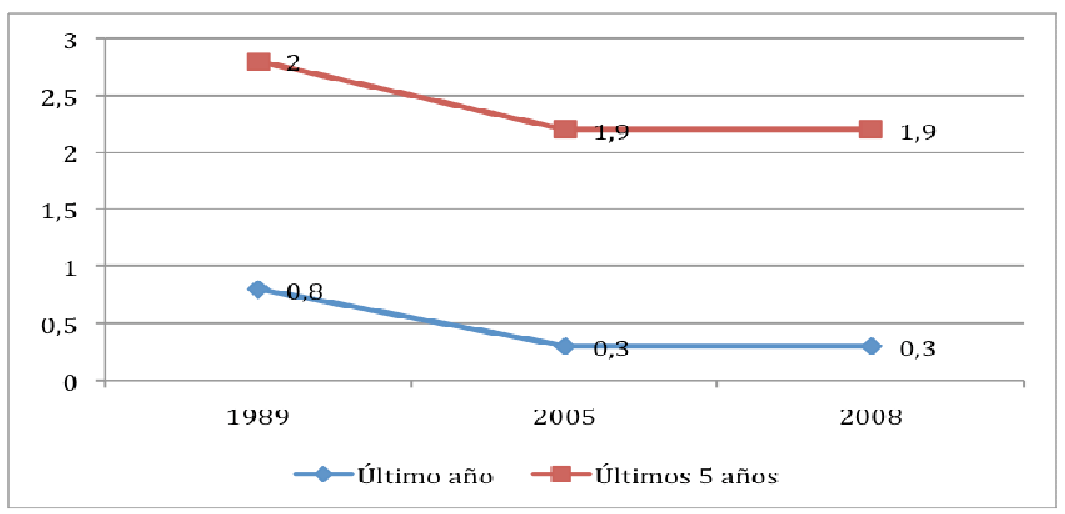

d. Robo de bicicletas

Las tasas de victimización en España de esta conducta delictiva durante los últimos cinco años fue del 3,9\% y durante 2008 del 0,8\%, índices algo superiores a los obtenidos por nuestro país en el pase internacional de la encuesta de victimización de 2005 , que quedaron representados por el 3,2\% y $0,7 \%$ respectivamente. Se aprecia en el gráfico $n^{\circ} 7$ una tendencia creciente de este tipo de conductas en el horizonte temporal del último año en cada pase de las encuestas; no así para los cinco últimos años. La tasa de denuncia en este delito es inferior, con carácter general, a la relativa a robo de otros vehículos, si bien en 2008 supera el porcentaje de denuncias del robo de moto (véase el apartado relativo a tasas de denuncias). 


\section{Gráfico n 7: Evolución de los robos de bicicletas (\%)}

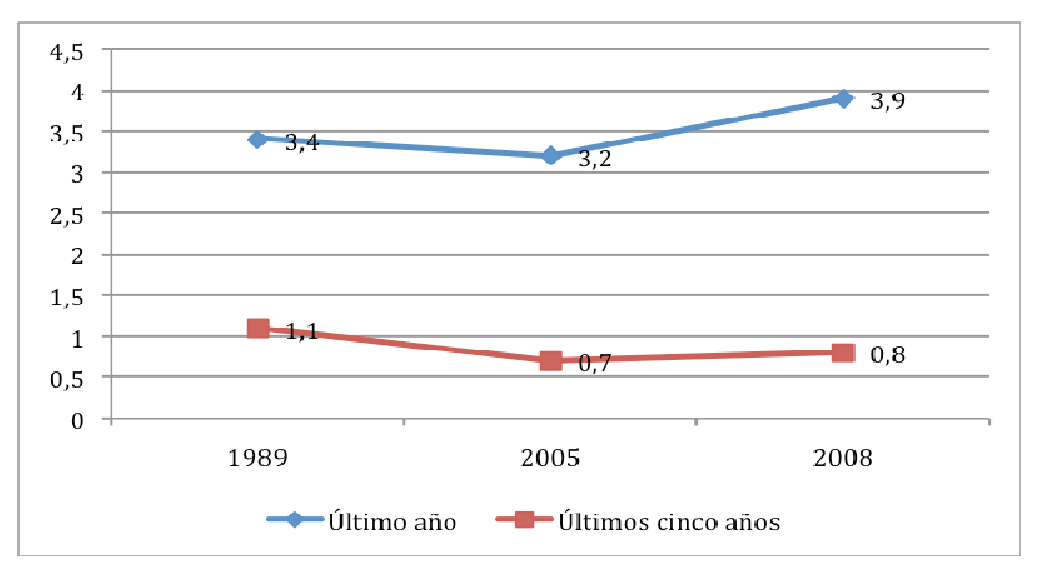

e. Robo en viviendas consumados e intentados

El informe de la encuesta de victimización realizada entre los países de la Unión Europea (EU ICS) en 2005 resalta que delitos como el robo consumado en vivienda fueron descendiendo en los 10 años anteriores a 2005 en la mayor parte de los países de la UE, incluida España. Atendiendo a los nuevos datos, parece que esta tendencia de descenso se ha mantenido en nuestro país si se observan los datos de los cinco años anteriores al pase de la encuesta de 2008. Los datos relativos al año anterior se mantienen relativamente estables en el último periodo (gráfico $\mathrm{n}^{\circ} 8$ ).

\section{Gráfico nº 8: Evolución de los robos consumados en viviendas}

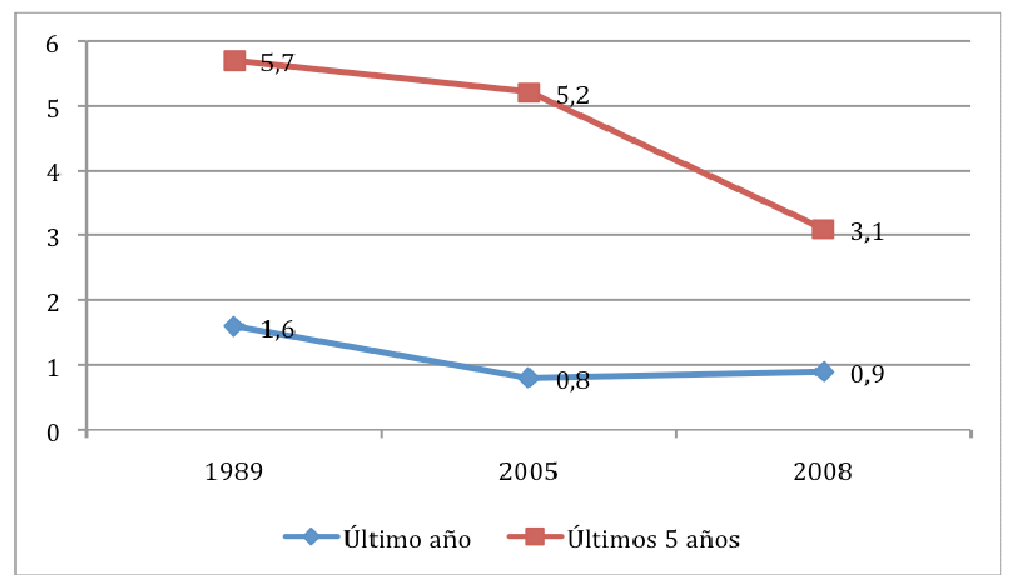

Si nos atenemos sólo a los robos que se han descrito como tentativas, la tasa de victimización en 2008 para el último año es de un $0,8 \%$ y para los cinco años anteriores de 3,9\% (gráfico $\mathrm{n}^{\mathrm{o}}$ 9). Si introducimos la comparación con anteriores encuestas, el descenso parece consolidarse en los datos relativos a los cinco años anteriores a los 
pases de las encuestas, mientras que la tasa de victimización del año anterior muestra un ligero ascenso respecto a 2005, pero no muy considerable.

\section{Gráfico n ${ }^{0}$ 9: Tasas de victimización de intentos de robo en vivienda en España}

$(\%)$

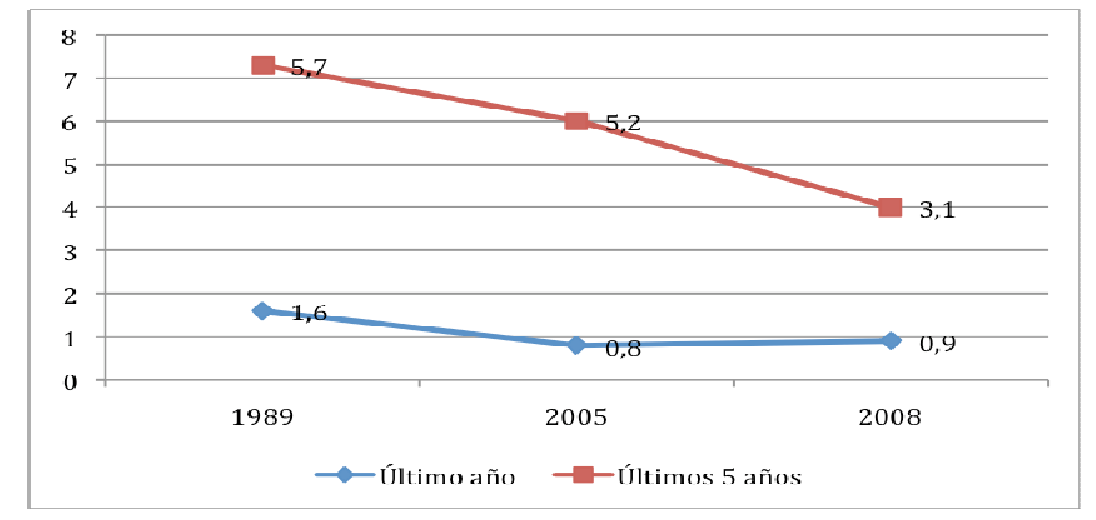

f. Robo con violencia e intimidación

El informe EU ICS 2005 comenta que los niveles de robo con violencia a nivel internacional no son muy altos y que la tendencia general es de descenso; resalta en esta dinámica la situación española, ya que su evolución entre 1989 y 2005 es llamativa (VAN DIJK, 2007:73). Si añadimos el nuevo dato aportado por la encuesta realizada por el ODA en 2008 parece que esta tendencia de descenso se ha mantenido en nuestro país, tanto si se observan los datos de los cinco años anteriores al pase de la encuesta, como si se analizan los referentes al año anterior (gráfico $\mathrm{n}^{\circ} 10$ ).

\section{Gráfico $n^{0}$ 10: Evolución del robo con violencia e intimidación en España}

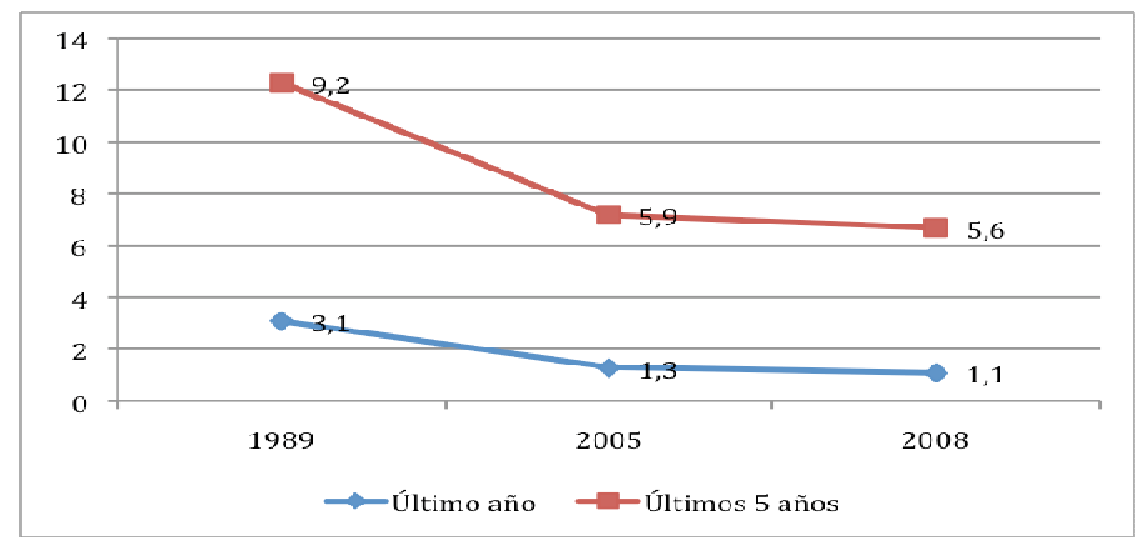




\section{g. Hurtos}

En las tasas relativas al año anterior al pase de la encuesta se observa cómo, tras un notable descenso en 2005, la victimización vuelve a ascender aunque a niveles notablemente más bajos que en 1989. Los datos que reflejan los cinco años anteriores muestran una mayor estabilidad.

\section{Grafico n 11: Evolución de las tasas de victimización de los hurtos}

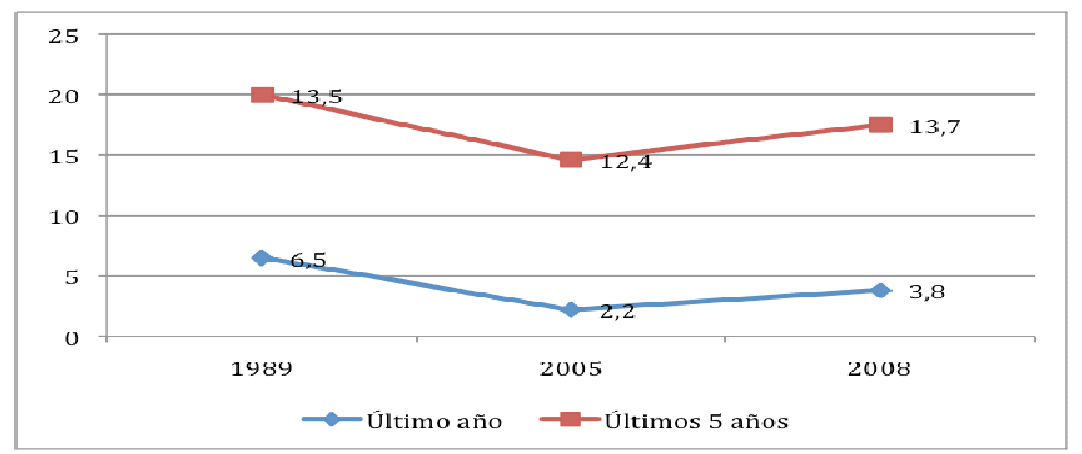

h. Agresiones y abusos sexuales

La secuencia de la victimización de este delito, teniendo en cuenta los dos pases de la encuesta internacional en que nuestro país participó, nos permite apreciar un mantenimiento de las tasas de prevalencia en 2005 y 2008, con un fuerte descenso desde 1989 (gráfico $n^{\circ}$ 12). A pesar de este hecho las tasas de denuncia en España de este delito en los últimos veinte años se han incrementado notablemente, dando lugar al positivo resultado de una menor cifra negra en este tipo de conductas delictivas.

\section{Gráfico n⿳ 12: Evolución de las agresiones y abusos sexuales (\%)}

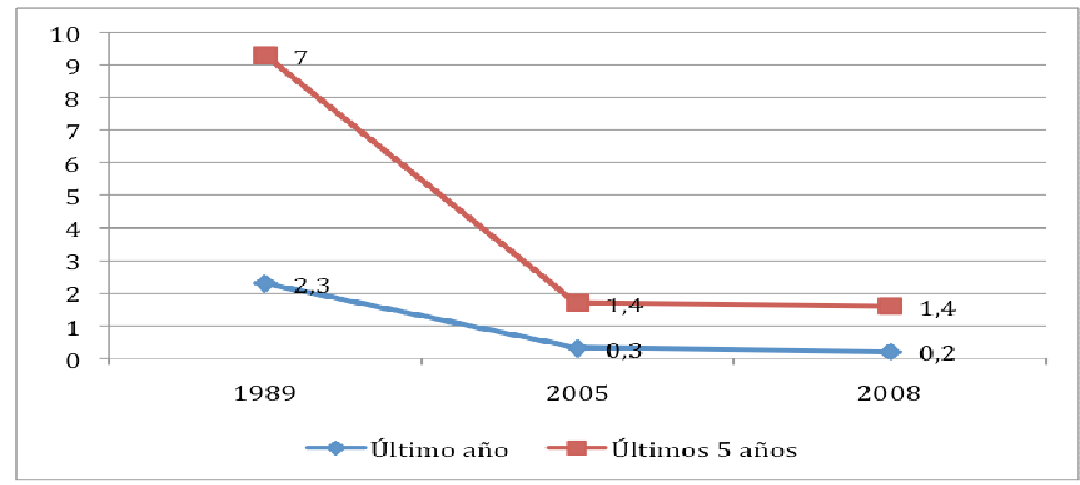




\section{i. Agresiones físicas y amenazas}

La comparación evolutiva nos ofrece un panorama interesante. Por un lado, está la información relativa al año anterior de cada encuesta, según la cual el nivel de agresiones físicas y amenazas es inferior al del año 1989, aunque con un descenso inferior al experimentado en el año 2005. Por su parte, la experiencia de las víctimas en cuanto a los delitos sufridos en los cinco años anteriores a la entrevista es totalmente diferente, puesto que el nivel de victimización actualmente es el más bajo de los tres años de pases de encuesta, tras haber sufrido un incremento en 2005 (gráfico ${ }^{\circ} 13$ ).

\section{Gráfico no 13: Tasas de victimización de agresiones físicas y amenazas en España}

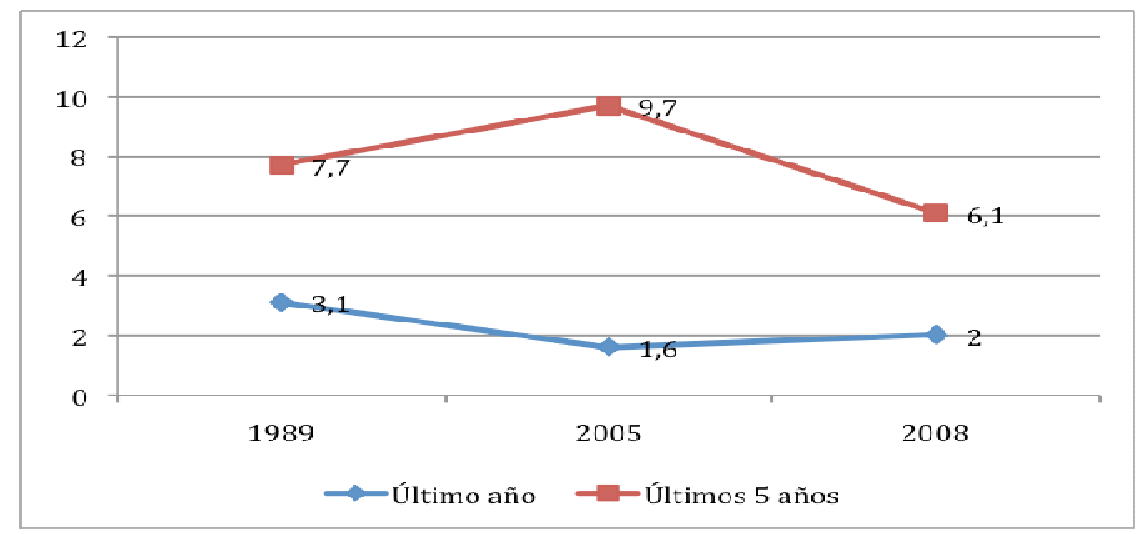

\section{c. Comparación de las tasas y evolución de las tipologías delictivas}

Si unimos en una sola figura la evolución de los distintos hechos delictivos podemos observar dos cuestiones interesantes: La primera es una comparativa de sus respectivas tendencias; y la segunda, el orden que cada tipología delictiva ocupa según las tasas de cada uno de esos sucesos.

Como se observa en el gráfico $\mathrm{n}^{\circ} 14$, la tipología que tiene una mayor tasa de victimización en España, a pesar del enorme descenso que ha experimentado en las últimas décadas, es el robo de objeto de coches. En segundo lugar se colocan los hurtos, con una trayectoria ascendente. Delitos violentos, como los robos con violencia e intimidación y las agresiones físicas y amenazas, presentan una tasa considerablemente menor, siendo la tendencia de ambos descendente, a pesar del repunte que los primeros tuvieron durante 2005. Los últimos puestos los ocupan el robo de bicicletas y las agresiones sexuales, tras descender en 2005 y mantener su tasa en 2008. 


\section{Gráfico n ${ }^{0}$ 14: Evolución de las tasas de victimización de las tipologías delictivas} (prevalencia 5 años)

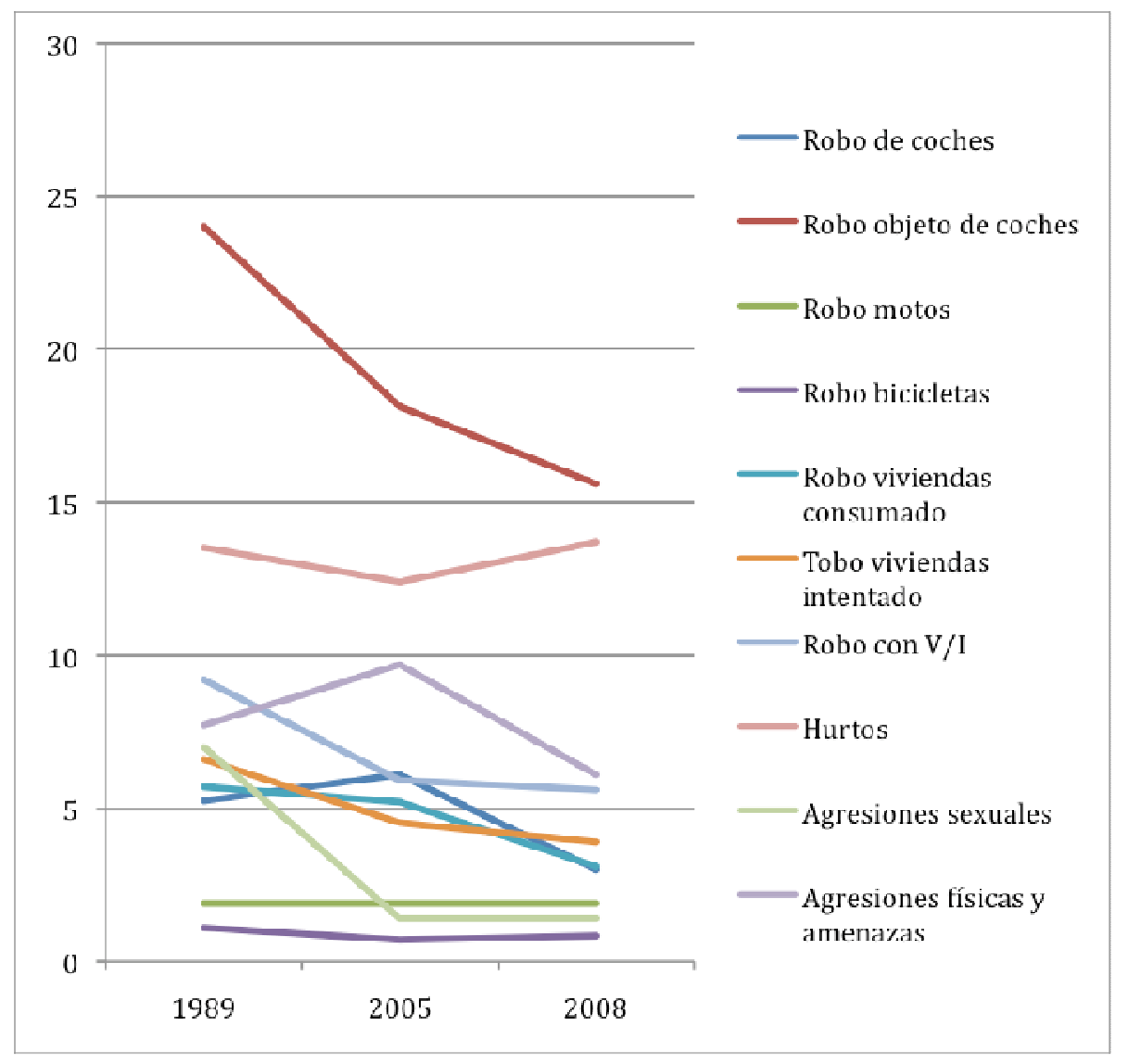

\section{Delitos totales sufridos por las víctimas}

La cantidad de delitos totales padecidos por las víctimas de la muestra estatal no coincide con el número de víctimas, puesto que una víctima puede haber sufrido más de un delito en el año anterior al pase de la encuesta, que es el intervalo de tiempo estudiado. La evolución de la tasa de delitos totales en España se muestra en el siguiente gráfico $n^{\circ} 15$ : 


\section{Gráfico no 15: Evolución de la tasa de los delitos totales en España (9 delitos)}

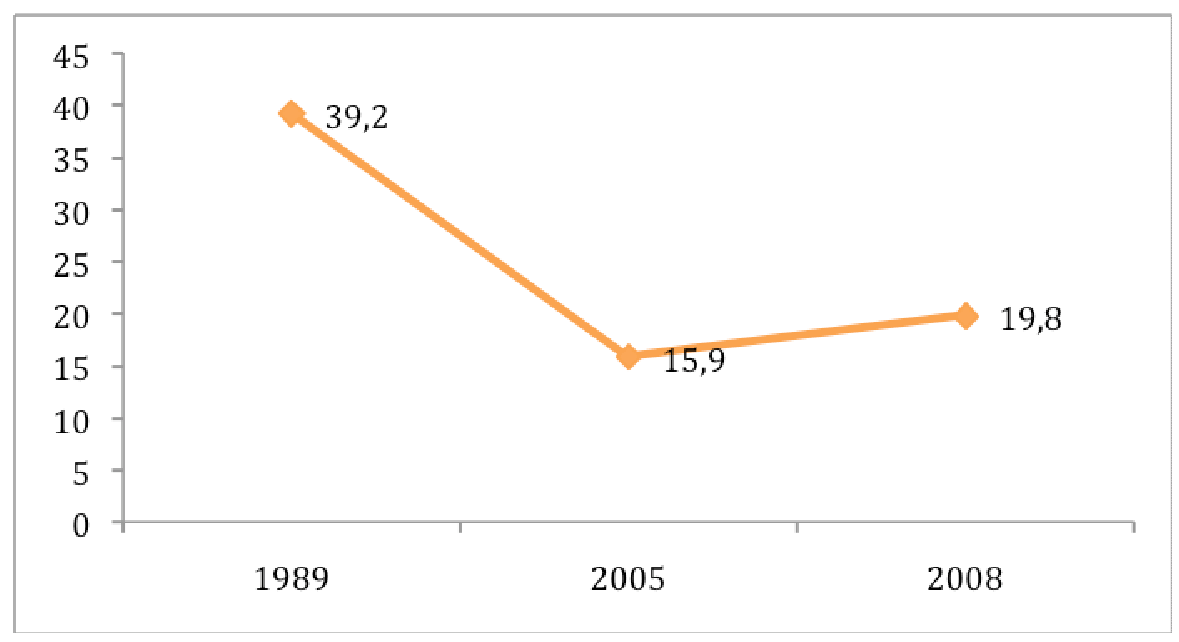

La evolución de la tasa de los delitos totales en el último año coincide con la tasa de victimización (véase gráfico $\mathrm{n}^{\circ} 3$ ), ya que en ambas tasas se produce un descenso importante entre 1989 y 2005 para después aumentar levemente entre 2005 y 2008.

Si desglosamos esa evolución por tipologías delictivas (tabla $\mathrm{n}^{\mathrm{o}} 1$ ) se observa que los delitos que tienen un movimiento similar a la tendencia de la tasa de delitos totales en general son los robo de objeto de coches, robo de bicicletas, robo en vivienda consumado, hurto, y agresiones y amenazas. Sólo en la tentativa de robo en vivienda la tendencia es ascendente desde 1989 hasta 2008. Por el contrario, presentan una evolución descendente desde 1989 los delitos de robo de coches, robo de motos y robo con violencia e intimidación.

Tabla $\mathbf{n}^{0}$ 1: Evolución de la tasa de los delitos totales en España según tipologías delictivas

\begin{tabular}{|l|c|c|c|}
\hline & $\mathbf{1 9 8 9}$ & $\mathbf{2 0 0 5}$ & $\mathbf{2 0 0 8}$ \\
\hline Robo coches & 1,9 & 1,5 & 1,3 \\
\hline Robo objeto coches & 14 & 3,7 & 5,9 \\
\hline Robo motos & 0,9 & 0,4 & 0,4 \\
\hline Robo bicis & 1,2 & 0,7 & 0,9 \\
\hline Robo vivienda & 2,1 & 1,1 & 1,5 \\
\hline $\begin{array}{l}\text { Tentativa robo } \\
\text { vivienda }\end{array}$ & 0 & 0,5 & 0,9 \\
\hline Robo con violencia & 4,4 & 1,7 & 1,5 \\
\hline Hurto & 6,5 & 2,2 & 4,6 \\
\hline Agresiones/amenazas & 6,2 & 2,8 & 3,5 \\
\hline
\end{tabular}




\section{Tasas de denuncia}

De las 682 víctimas de la muestra de 2008, 326 denunciaron el hecho a la policía en los últimos cinco años. Esto significa que la tasa de denuncia para ese periodo de tiempo es de $47,9 \%$.

En los pases internacionales de 1989 y 2005 se aporta la tasa de denuncia referente al último año anterior al pase de cada encuesta, y referida solo a 9 delitos de los 11 que recoge el cuestionario ICVS. Con el fin de poder conocer la tendencia de las tasas de denuncia en España hemos procedido a realizar el cálculo de la tasa de denuncia en 2008 para esos 9 delitos. El resultado se expone en el gráfico $n^{\circ} 16$ :

Gráfico no 16: Tendencia de las tasas de denuncias en España en el último año y para 9 delitos (\%)

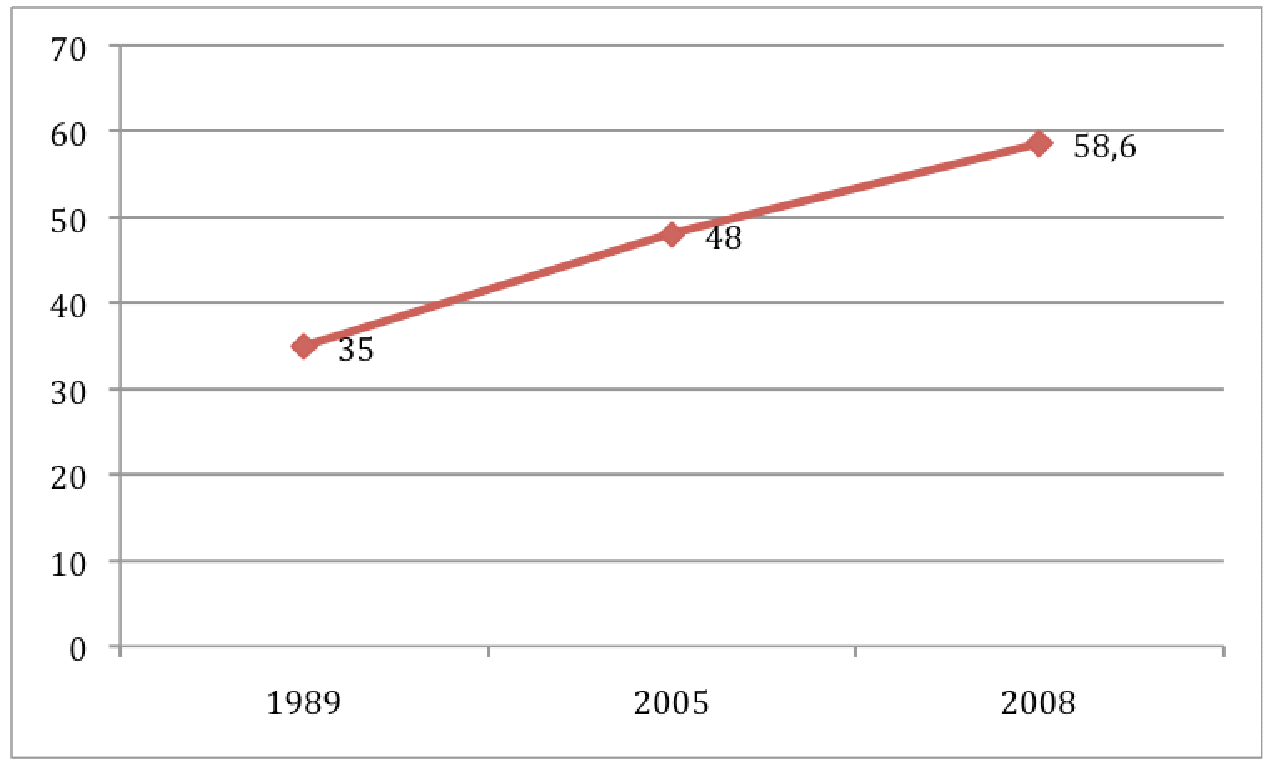

Más allá de la tendencia ascendente que muestran estas tasas, resulta interesante apuntar algunos resultados referentes a la relación entre la victimización y los hechos denunciados, así como sobre los motivos de la denuncia. Dichos resultados nos ayudan a entender la diferente tendencia de la delincuencia mostrada por las estadísticas oficiales y por las encuestas de victimización. 
Los hechos que las víctimas denunciaron a la policía más habitualmente durante los últimos 5 años anteriores a 2008 fueron el robo de coches $(90,5 \%)$, robo de motos $(76,9 \%)$ y robo consumado en viviendas $(63,6 \%)$. El hecho que tiene una tasa menor de denuncias es el "daño a coches". Véase la tabla n 2.

Tabla ${ }^{0}$ 2: Tasas de victimización y denuncia según categorías delictivas y temporalidad en España (\%)

\begin{tabular}{|l|l|l|l|}
\hline & $\begin{array}{l}\text { Tasa victimización } \\
\text { último año }\end{array}$ & $\begin{array}{l}\text { Tasa victimización } \\
\text { últimos 5 años }\end{array}$ & $\begin{array}{l}\text { Tasa denuncia } \\
\text { últimos 5 años }\end{array}$ \\
\hline Robo coches & 0,8 & 3 & 90,5 \\
\hline Robo objeto coches & 4,4 & 15,6 & 44,3 \\
\hline Daños a coches & 8,9 & 25,9 & 18 \\
\hline Robo motos & 0,3 & 1,9 & 76,9 \\
\hline Robo bicicletas & 0,8 & 3,9 & 27,8 \\
\hline Robo vivienda & 0,9 & 3,1 & 63,6 \\
\hline $\begin{array}{l}\text { Tentativa robo } \\
\text { vivienda }\end{array}$ & 0,8 & 3,9 & 23,6 \\
\hline Robo con violencia & 1,1 & 5,6 & 50,6 \\
\hline Hurtos & 3,8 & 13,7 & 52,1 \\
\hline Agresiones sexuales & 0,2 & 1,4 & 30 \\
\hline Agresiones/amenazas & 2 & 6,1 & 40,7 \\
\hline TOTAL & $\mathbf{1 7 , 4}$ & $\mathbf{4 8 , 7}$ & $\mathbf{4 7 , 9}$ \\
\hline
\end{tabular}

En el gráfico $\mathrm{n}^{\mathrm{o}} 17$ se puede observar cómo se distribuyen las tasas de victimización de los delitos más relevantes y compararlo con el gráfico $\mathrm{n}^{\mathrm{o}} 18$ que representa los hechos que tienen mayores tasas de denuncia. Los resultados de dicha comparación muestran que no se corresponde la victimización delictiva con las denuncias o hechos que las víctimas ponen en conocimiento de la policía, ya que la victimización se expande hacia la derecha abarcando especialmente los daños a coches y los robos de objetos de coches, mientras que las denuncias tienen una distribución vertical en la estructura de tela de araña. 


\section{Gráfico n 17: Tasas de victimización en los últimos 5 años en España (\%)}

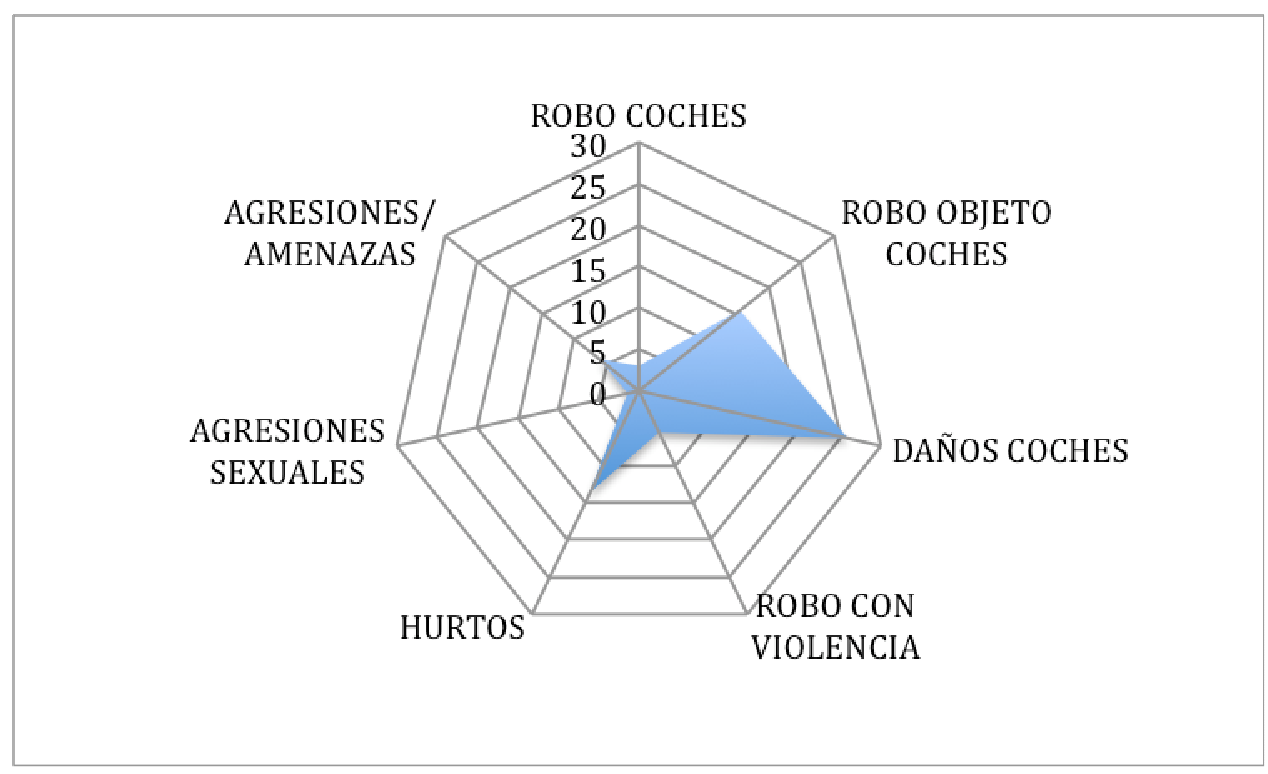

Gráfico $n^{0}$ 18: Tasas de denuncias en los últimos 5 años en España (\%)

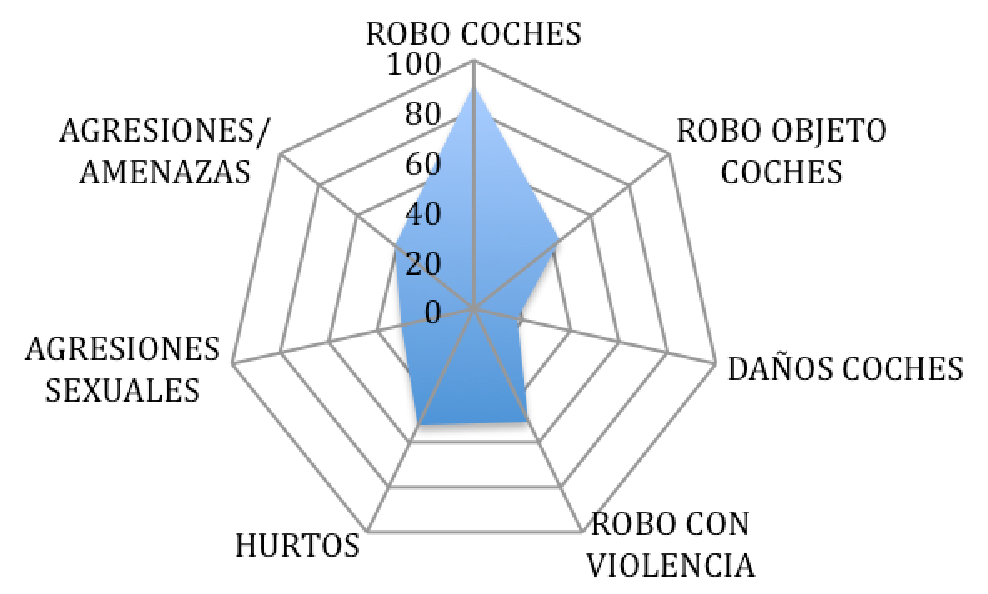

En cinco de las once infracciones se pregunta también por el motivo que llevó a la víctima a denunciar el suceso. Dichos delitos son el robo con violencia, agresión sexual, robo de objeto de coche, robo en viviendas y agresiones físicas y amenazas (tabla $\mathrm{n}^{\mathrm{o}} 3$ ). Esta pregunta permite multirrespuestas, por lo que los totales no suman $100 \%$. 
Tabla no 3: Motivos de la interposición de la denuncia según infracciones (\%)

\begin{tabular}{|c|c|c|c|c|c|}
\hline & $\begin{array}{c}\text { Robo } \\
\text { objeto de } \\
\text { coche }\end{array}$ & $\begin{array}{c}\text { Robo en } \\
\text { vivienda }\end{array}$ & $\begin{array}{c}\text { Robo con } \\
\text { violencia }\end{array}$ & $\begin{array}{c}\text { Agresión } \\
\text { sexual }\end{array}$ & $\begin{array}{c}\text { Agresión } \\
\text { física/amenaza }\end{array}$ \\
\hline $\begin{array}{c}\text { Recuperar } \\
\text { objeto }\end{array}$ & 32 & 19,3 & 46,3 & -- & 1,9 \\
\hline Tenía seguro & 44,3 & 14 & 19,5 & -- & -- \\
\hline $\begin{array}{c}\text { Debe } \\
\text { denunciar }\end{array}$ & 44,3 & 29,8 & 51,2 & 50 & 26,4 \\
\hline $\begin{array}{c}\text { Detener al } \\
\text { autor }\end{array}$ & 7,2 & 14 & 22 & 50 & 18,9 \\
\hline $\begin{array}{c}\text { No vuelva a } \\
\text { ocurrir }\end{array}$ & 13,4 & 17,5 & 26,8 & -- & 26,4 \\
\hline Recibir ayuda & 1 & 1,8 & -- & 16,7 & 17 \\
\hline Indemnización & 1 & -- & -- & -- & -- \\
\hline Otras & 6,2 & 3,5 & 2,4 & -- & 9,4 \\
\hline
\end{tabular}

De los ocho motivos en los que se dividen las respuestas, la mayoría de los entrevistados denunciaron por considerar que era un hecho que debe ser puesto en conocimiento de la policía, quedando a cierta distancia el resto de motivos (véase gráfico $\left.n^{0} 19\right)$.

\section{Gráfico n ${ }^{0}$ 19: Motivos de la denuncia (\%)}

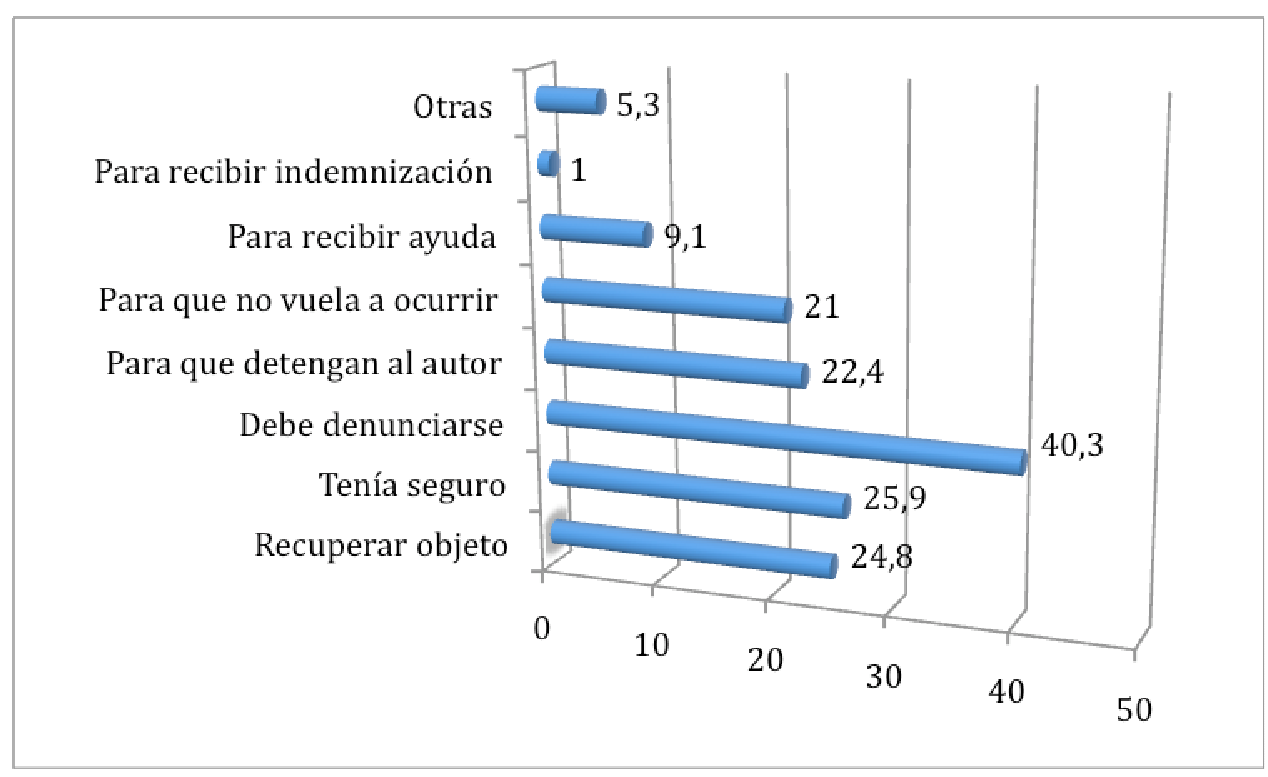

Pero el resultado cambia ligeramente si agrupamos los siete motivos principales, excluyendo la categoría "otras", en tres grandes grupos: Altruistas, en donde tienen cabida las respuestas "debe denunciarse" y "para que no vuelva a ocurrir"; económicos, que incluye la respuestas "tenía seguro", "para recuperar los objetos", "para recibir

Revista Española de Investigación Criminológica 
ayuda" y "para recibir una indemnización"; y retributivos, que contiene la respuesta "quería que detuvieran al autor". Con esta nueva agrupación, la motivación "económica", alusiva a los intereses de la víctima en subsanar o compensar el daño producido por la infracción penal, adquiere una relevancia similar a los motivos "altruistas", presentando ambos porcentajes bastante superiores a la de los motivos "retributivos".

\section{Delincuencia percibida y medios de comunicación}

El segundo objetivo propuesto en este trabajo era comprobar si la percepción social del volumen de delincuencia se corresponde con la realidad delictiva. El 88,8\% de los encuestados cree que la delincuencia ha aumentado mucho o bastante en los últimos años, como se aprecia en el gráfico $\mathrm{n}^{\circ} 20$.

\section{Gráfico no 20:¿Cree que en los últimos años la delincuencia ha crecido?}

(\%)

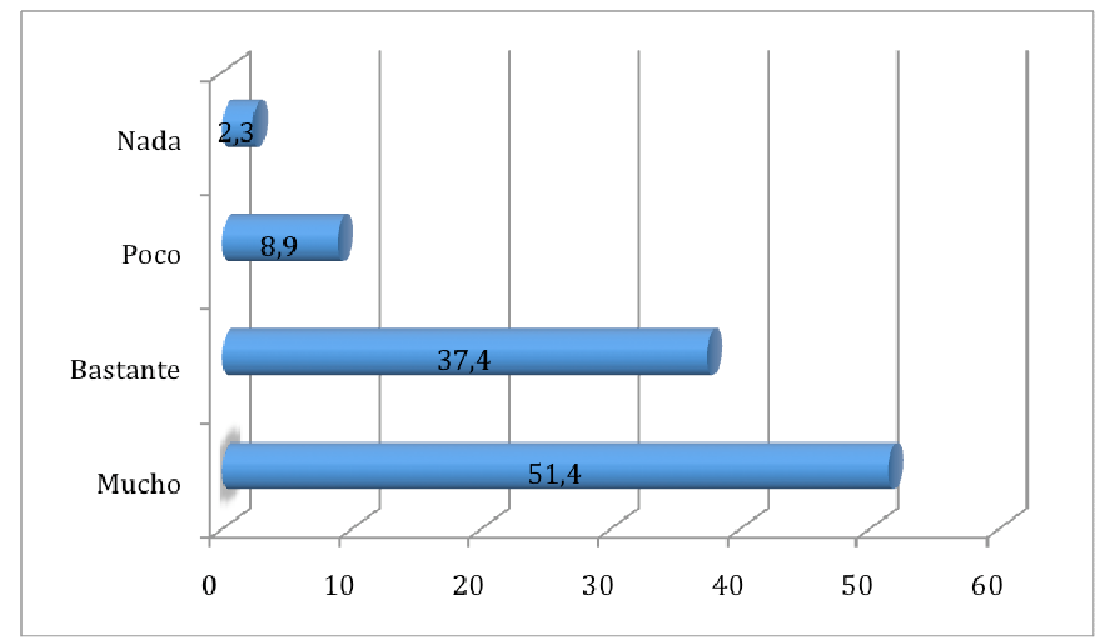

Esta opinión discrepa considerablemente de las conclusiones de nuestro trabajo, pues ya hemos visto que los resultados de nuestra encuesta muestran, comparados con los de las encuestas de 1989 y 2005, que la delincuencia ha disminuido.

Estudios anteriores han alcanzado la conclusión de que si bien la percepción del riesgo de victimización es un factor relevante a la hora de entender el miedo al delito (Medina, 2003), la explicación de éste tiene poca relación con procesos afectivos (SAN JUAN et al, 2005) o con la criminalidad registrada judicialmente (VOZMEDIANO y 
SAN JUAN, 2006). De hecho, es bien sabido que la delincuencia objetivable y la percepción de seguridad son fenómenos no necesariamente dependientes (VOZMEDIANO, 2008). Otras líneas de investigación se han centrado en la relación existente entre los programas televisivos violentos y el miedo al delito (entre otros, ROMER et al, 2003). Estudios realizados en España comparando el volumen de hechos conocidos por la policía y los índices de preocupación y miedo al delito obtenidos de las encuestas del CIS concluyen que no existe una correspondencia entre ambos fenómenos y que esa discordancia puede ser fruto de la función ejercida por los medios de comunicación (SOTO, S., 2005; RECHEA, C. et al 2004). Ahondando en los motivos que llevan a la ciudadanía a considerar que la delincuencia ha aumentado, cuando en realidad ha disminuido en los últimos 20 años, se ha buscado, inspirados en estudios precedentes, la relación entre la frecuencia de noticias sobre delitos recibidas a través de los medios de comunicación en general y la delincuencia percibida, a partir de la inclusión de preguntas nuevas en el cuestionario ICVS.

Así fue como preguntamos también ¿con qué frecuencia recibe noticias de delincuencia? Los resultados muestran que el 92,8\% de los encuestados recibe noticias sobre delincuencia casi todos los días, seguido muy de lejos por los que las reciben una vez por semana (5\%), una vez al mes $(0,5 \%)$ o con menos frecuencia $(0,7 \%)$.

Al cruzar los datos anteriores (opinión sobre crecimiento de la delincuencia y frecuencia con que recibe noticias de delincuencia), obtenemos que los ciudadanos que reciben información delictiva casi a diario son los que en mayor medida $(53,2 \%)$ opinan que la delincuencia ha aumentado considerablemente, siendo las diferencias estadísticamente significativas $\left(x^{2}=46,561^{a} ; g l=9\right.$; $\left.\operatorname{sig}=, 000\right)$. Por el contrario, no se han encontrado diferencias significativas que permitan relacionar la visión pesimista de la delincuencia con una previa victimización.

Los resultados, por tanto, apuntan a que la visión distorsionada del volumen de delincuencia en España puede deberse en parte a la reiterada información de hechos delictivos que los ciudadanos reciben a través de los medios de comunicación.

\section{CONCLUSIONES}

La evolución de la delincuencia común en España, hallada a través de las encuestas de victimización, presenta una tendencia descendente entre 1989 y 2008. De

Revista Española de Investigación Criminológica

Artículo 2, Número 8 (2010) $\quad$ www.criminología.net

ISSN: $1696-9219$ 
hecho, la tasa de victimización hallada para los últimos cinco años anteriores al pase de cada una de las tres encuestas de victimización realizadas desde la primera de esas fechas ha descendido en casi 9 puntos, y la del último año ha bajado en algo más de 10 . Por su parte, la tasa de delitos totales subió ligeramente entre 2005 y 2008, aunque no tanto como lo que bajó entre 1989 y 2005.

La evolución de la tasa de victimización es descendente para todas las categorías delictivas, salvo para los hurtos. Sin embargo, si atendemos a la tasa de delitos totales, vemos que, aunque en la mayoría de los delitos desciende o se mantiene, la tentativa de robo en vivienda presenta una tendencia al alza. Con esto se concluye que sólo han aumentado las víctimas que padecen un hurto y que la tentativa de robo en viviendas es el delito que más aumentado de la minoría de delitos que se incrementan.

Por otro lado, hay que destacar que las tasas de victimización y denuncia presentan tendencias diferentes, siendo la primera descendente y la segunda ascendente. Esto muestra un indicio de correlación negativa entre la tasa de victimización y el hecho de que la víctima ponga lo sucedido en conocimiento de la policía (denuncia). No obstante, si los datos oficiales recogen los hechos conocidos por la policía y una de las formas que la policía tiene de alcanzar dicho conocimiento es a través de las denuncias de las víctimas, el ascenso de la tasa de denuncias que hallamos en nuestro estudio podría ser una de las causas que explique el aumento de la delincuencia según las estadísticas policiales.

En este pase de la encuesta a nivel nacional hemos incluido preguntas nuevas para ahondar en los motivos que llevan a la ciudadanía a considerar que la delincuencia ha aumentado, cuando según las tasas de victimización ha disminuido en los últimos 20 años. Para ello hemos inquirido sobre la información que los encuestados reciben a diario por los medios de comunicación sobre delincuencia. Los resultados apuntan a que la visión distorsionada del volumen de delincuencia en España puede deberse en parte a la reiterada información de hechos delictivos que los ciudadanos reciben a través de los medios de comunicación, más que al hecho de haber sido ellos o personas cercanas víctimas de un delito. 
En cualquier caso, y más allá de las hipótesis que puedan extraerse de los resultados de este trabajo, insistimos en el hecho de que la política criminal española debería contar con información complementaria a las estadísticas oficiales de delincuencia en los procesos de reforma legislativa penal, ya que dichas estadísticas no caracterizan la totalidad de la delincuencia. 


\section{BIBLIOGRAFÍA}

ALVIRA MARTIN/ RUBIO RODRÍGUEZ (1982). "Victimización y Seguridad. La perspectiva de la encuestas de victimización en España". REIS, $\mathrm{n}^{\circ} 18$. Pp. 2950.

BAS/ GARCÍA-VALDECASAS (2003). VIII Congreso Internacional del CLAD sobre la reforma del Estado y de la Administración pública, Panamá.

BOUTEN, E., GOUDRIAAN, H. y NIEUWBEERTA, P. (2003): "Victimación delictiva en 17 países industrializados" en Revista Española de Investigación Criminológica. REIC NI02-03. http://www.criminologia.net

CID MOLINE, J. (2008). "El incremento de la población reclusa en España entre 1996 y 2006: Diagnóstico y remedios". Revista Española de Investigación Criminológica, núm. 6.

DÍEZ RIPOLLÉS, JL (1996). Delincuencia y víctimas. Tirant lo Blanch. Valencia.

DÍEZ RIPOLLÉS, J.L.(2006). "Algunos rasgos de la delincuencia en España a comienzos del siglo XXI" en Revista Española de Investigación Criminológica, núm. 4.

DÍEZ RIPOLLÉS, J.L. / GARCÍA ESPAÑA, E. (Dirs) (2009): Encuestas a víctimas en España. IAIC-Fundación Cajasol.

EU ICS report (2005). The Burden of Crime in the EU, A Comparative Analysis of the European Survey of Crime and Safety (EU ICS).

GARCÍA ESPAÑA, E; PÉREZ JIMÉNEZ, F. (2004). "Reciente evolución de la delincuencia en Andalucía" en Revista Electrónica de Ciencia penal y Criminología. 06-04.

GARCÍA ESPAÑA, E./ PÉREZ JIMÉNEZ, F./ BENÍTEZ JIMÉNEZ, M.J. (2006) La delincuencia según las víctimas: un enfoque integrado a partir de una encuesta de victimización. Edit. Fundación el Monte y el IAIC. Málaga.

GARCÍA ESPAÑA, E./ PÉREZ JIMÉNEZ, F./ BENÍTEZ JIMÉNEZ, M.J. (2007). La delincuencia en Córdoba, Huelva y Sevilla. Una encuesta de victimización. Edit. Cajasol Obra social y el IAIC. Málaga.

GARCÍA ESPAÑA, E.; PÉREZ JIMÉNEZ, F.; BENÍTEZ JIMÉNEZ, MJ. (2008). La delincuencia en las capitales andaluzas. Encuestas de victimización en Andalucía. IAIC-Fundación Cajasol.

GARCÍA PÉREZ, O. (2008). "La reforma de 2006 del sistema español de justicia penal de menores" en Revista Electrónica Semestral de Políticas Públicas en Materias Penales, núm. 5.

GIDDENS, A. (1991). Sociología. Alianza Universidad Textos. Madrid.

HAGAN, F.E. (1989). "Research Methods in Criminal Justice and Criminology". 2a edición. Macmillan Publishing Company. Nueva York.

HEIMER, K.; LAURITSEN, J.L.; y LYNCH, J.P. (2009). "The National Crime Victimization Survey and the Gender Gap in Offending: Redux". Criminology. Vo. 47. Num. 2.

JOHNSON, H. (2006). http://www.aic.gov.au/documents/9/D/F/\%7B9DFFC106-12D64576-9D51-045C9BD39BEC\%7Drpp64.pdf Página consultada el 17 de diciembre de 2009.

MEDINA, J. (2003). "Inseguridad ciudadana, miedo al delito y policía en España" en RECPC 05-03.

Revista Española de Investigación Criminológica

Artículo 2, Número 8 (2010) $\quad$ www.criminología.net

ISSN: $1696-9219$ 
MIRANDA LÓPEZ, M.J. (1993). "Problemas metodológicos en las encuestas de victimización: lo que muestran y lo que esconden". Victimología femenina: asignaturas pendientes para una nueva ciencia. $14^{\circ}$ curso de verano en San Roque.

RECHEA ALBEROLA, C., BENÍTEZ JIMÉNEZ, M.J., FERNÁNDEZ MOLINA, E.(2004) "La inseguridad ciudadana y la delincuencia en España". Informe publicado por el Instituto Universitario de Investigación sobre Seguridad Interior, Madrid.

REDONDO, S./ LUQUE, E./ TORRES, N. /MARTÍNEZ, M.(2006). Estudios comparativo de los sistemas penitenciarios europeos. Memoria de investigación no publicada. Departamento de Personalidad, Evaluación y Tratamiento Psicológico. Facultad de Psicología. Universidad de Barcelona.

ROMER, D. / JAMIESON, K.H. / ADAY, S. (2003). "Are We Being Mugged by Local News? Television News and the Cultivation of Fear of Crime". Journal of Communication, 53 (1).

SAN JUAN, C. / VERGARA, A.I. / GERMÁN, I. (2005). "Propiedades psicométricas de un cuestionario para la evaluación de la calidad de vida urbana y el miedo al delito" en REIC, 01-05.

SCHWART, J.; STEFFENSMEIER, D.; ZHOG, H.; y ACKERMAN, J. (2009). "Trends in the Gender Gap in Violence: Revaluating NCVS and other evidence". Criminology. Vo. 47. Num.2.

SOTO NAVARRO, S. (2005). "La influencia de los medios en la percepción social de la delincuencia". Revista electrónica de Ciencia penal y Criminología, $\mathrm{n}^{\mathrm{0}} 7$.

VAN DIJK, J./ VAN KESTEREN, J./ SMIT, P. (2007). Criminal Victimization in International Perspective, 2004-2005. Edit. WODC.

VOZMEDIANO, L. y SAN JUAN, C. (2006). "Empleo de sistemas de información geográfica en el estudio del medio al delito" en REIC, $\mathrm{n}^{\circ} 4$.

VOZMEDIANO, L. / SAN JUAN, C./ VERGARA, A.I. (2008). "Problemas de mediación del miedo al delito" en RECPC 10-07. 